\title{
AMOSTRAGEM PARA AVALIAÇÃO DA FERTILIDADE DO SOLO EM FUNÇÃO DO INSTRUMENTO DE COLETA DAS AMOSTRAS E DE TIPOS DE PREPARO DO SOLO ${ }^{(1)}$
}

\author{
Fábio Henrique Tavares de Oliveira ${ }^{(2)}$, Jandeilson Alves de Arruda ${ }^{(3)}$, Ivandro \\ de França da Silva ${ }^{(2)}$ \& Jailson do Carmo Alves ${ }^{(4)}$
}

\begin{abstract}
RESUMO
As medidas da média e da variabilidade dos índices de fertilidade do solo podem variar com o instrumento de coleta das amostras e com o tipo de preparo do solo. Assim, é necessário o desenvolvimento de métodos de amostragem de solo que melhor representem as reais condições de fertilidade do solo. Este trabalho teve como objetivos avaliar os efeitos da pá de corte e do trado de caneca nas medidas da média e da variabilidade de índices de fertilidade do solo sob plantio direto (PD) e preparo convencional (PC), estimar o número de amostras simples para formar uma composta e testar a hipótese de que a média aritmética das amostras simples é igual ao resultado da análise química da amostra composta. Foram coletadas amostras de um Luvissolo Crômico Pálico abrúptico em um experimento de comparação de tipos de preparo do solo, semeado com monocultura de milho. Coletaram-se 48 amostras simples de solo em uma parcela de $81 \mathrm{~m}^{2}$ sob PD, sendo 24 com pá de corte (perpendicularmente aos sulcos e no espaço compreendido entre os pontos médios entre sulcos) e $24 \mathrm{com}$ trado de caneca, em amostragem localizada (quatro amostras coletadas no sulco de plantio, oito a $10 \mathrm{~cm}$ do sulco e 12 no ponto médio entre os sulcos), próximas aos locais das amostras coletadas com pá de corte. Em outra parcela sob PC adotou-se o mesmo procedimento. A partir dessas amostras simples, foram preparadas, para cada combinação entre tipos de preparo do solo e instrumentos de coleta, amostras compostas de diferentes números de amostras simples $(4,8,12,16$ e 24 amostras simples/amostra composta), com três repetições. Em todas as amostras simples e compostas, determinaram-se o pH e os teores de $\mathrm{P}, \mathrm{K}^{+}, \mathrm{Ca}^{2+}, \mathrm{Mg}^{2+}$ e matéria orgânica. As características avaliadas em amostras coletadas com trado de caneca apresentaram maior variabilidade do que quando foram avaliadas em amostras
\end{abstract}

\footnotetext{
(1) Recebido para publicação em setembro de 2005 e aprovado em março de 2007.

(2) Professor Adjunto do Departamento de Solos e Engenharia Rural do Centro de Ciências Agrárias da Universidade Federal da Paraíba - UFPB. CEP 58397-000 Areia (PB). E-mail: fhtoliveira@hotmail.com

(3) Aluno do Curso de Agronomia do CCA/UFPB. Bolsista do PIBIC/CNPq. E-mail: jandeilson_agro@yahoo.com.br

(4) Mestrando do Programa de Pós-Graduação em Manejo de Solo e Água, CCA/UFPB. E-mail: jailson_agro@yahoo.com.br
} 
coletadas com pá de corte, independentemente do tipo de preparo do solo. Nos dois instrumentos de coleta, a ordem decrescente de variabilidade foi: $\mathrm{P}>\mathrm{Mg}^{2+}>\mathrm{K}^{+}>\mathrm{Ca}^{2+}>\mathrm{MO}>\mathrm{pH}$. A fertilidade média de uma parcela sob $\mathrm{PD}$ ou sob $\mathrm{PC}$ após a colheita e antes do preparo do solo subseqüente pode ser avaliada com trado de caneca, em substituição à pá de corte, desde que na preparação da amostra composta de solo 17 \% das amostras simples sejam coletadas no sulco de plantio, $33 \%$ a $10 \mathrm{~cm}$ do sulco e $50 \%$ no ponto médio entre os sulcos. A fertilidade média de uma parcela sob PD ou PC depois da colheita e antes do preparo do solo subseqüente, avaliada pela análise química da amostra composta, é semelhante àquela avaliada pela média aritmética dos resultados das análises químicas das amostras simples coletadas com pá de corte ou com trado de caneca de forma dirigida. Em geral, a coleta de pelo menos oito amostras simples de solo realizada com pá de corte ou trado de caneca de forma dirigida, conforme utilizado neste trabalho, seria suficiente para formar uma amostra composta representativa para avaliação da fertilidade do solo de uma unidade de amostragem aparentemente homogênea. Entretanto, quanto maior o número de amostras simples coletadas, maior será a confiabilidade ou exatidão da estimativa dessa fertilidade média.

Termos de indexação: análise de solo, plantio direto, trado de caneca.

\title{
SUMMARY: SAMPLING FOR SOIL FERTILITY EVALUATION AS INFLUENCED BY SAMPLING TOOL AND SOIL TILLAGE
}

\begin{abstract}
The measures of the average and variability of soil fertility indexes can vary with the sampling tool and soil tillage type. Soil sampling methods must be developed that are more reliable to represent the real conditions of soil fertility. This study aimed at an evaluation of the effects of the cutting shovel and hand auger on measures of average and variability of the soil fertility index (a) under no-tillage (NT) and conventional tillage (CT), (b) to estimate the minimum number of simple samples to form a composite sample and (c) to test the hypothesis that the arithmetic average of simple samples is equal to the result of the chemical analysis of the composite sample. Chromic Luvisol samples were collected in a control experiment of soil tillage type, planted with corn. In a $81 \mathrm{~m}^{2} \mathrm{plot}$ under NT 48 simple soil samples were collected, 24 with a cutting shovel (perpendicularly to the furrow and in-between two furrows) and 24 with auger hole, in controlled sampling (four samples collected in the planting furrow, 8 to $10 \mathrm{~cm}$ away from the furrow and $12 \mathrm{in}$ between the furrows), close to the points of sampling with the cutting shovel. The procedure was repeated in a second plot under CT. Composite samples of different numbers of simple samples $(4,8,12,16$ and 24 simple samples/composite samples), with three repetitions were prepared for each combination of soil tillage type - collection tool. The $\mathrm{pH}$ and the contents of $\mathrm{P}, \mathrm{K}^{+} \mathrm{Ca}^{2+}, \mathrm{Mg}^{2+}$ and organic matter $(\mathrm{OM})$ were determined in all simple and composite samples. The variability of the evaluated characteristics in samples collected with auger hole was greater than with the cutting shovel, independent of the soil tillage type. For both collection tools, the decreasing order of variability was: $P>\mathrm{Mg}^{2+}>\mathrm{K}^{+}>\mathrm{Ca}^{2+}>\mathrm{OM}>\mathrm{pH}$. The medium fertility of a field under NT or under $C T$ after the crop and before subsequent soil preparation can be evaluated with the auger hole, substituting the cutting shovel, if the composite sample consists of $17 \%$ of simple samples collected in the planting furrow, $33 \%$ at a distance of $10 \mathrm{~cm}$ from the furrow and $50 \%$ in the middle between the furrows. The mean fertility of a field under NT or CT after the crop and before the subsequent soil preparation, evaluated by the chemical analysis of the composite sample, is similar to that evaluated by the arithmetic average of the chemical analyses of the simple samples collected with cutting shovel or with auger hole in a controlled manner, as used here. In general, a minimum of eight simple samples collected with cutting shovel or hand auger would be enough to form a representative composite sample for evaluation of the soil fertility of a unit of seemingly homogeneous sampling. However, the higher the number of collected simple samples, the more reliable or accurate is the medium fertility estimate.
\end{abstract}

Index terms: Soil analysis, no-tillage, hand auger. 


\section{INTRODUÇÃO}

A variabilidade espacial de características químicas do solo ocorre naturalmente como conseqüência de processos pedogenéticos (Mausbach \& Wilding, 1991), manifestando-se nas direções horizontal e vertical, mas pode ser alterada pelas ações antrópicas, mediante o manejo do solo (James \& Wells, 1990). Em Latossolo Vermelho do cerrado de Minas Gerais, Santos \& Vasconcelos (1987) observaram que a aração e gradagem do solo de área recém-desmatada aumentou a variabilidade dos valores de $\mathrm{pH}, \mathrm{Al}^{3+}, \mathrm{Ca}^{2+} \mathrm{e} \mathrm{Mg}^{2+}$, porém a realização de uma nova gradagem para incorporação do calcário fez com que essa variabilidade diminuísse. Nesse mesmo solo, foi verificado que a variabilidade dos valores de teor de $\mathrm{P}$ diminuiu quando se procedeu à aração e gradagem do terreno, mas aumentou após a adubação fosfatada, principalmente quando esta foi localizada no sulco de plantio (Vasconcelos et al., 1982; Santos \& Vasconcelos, 1987).

A aplicação localizada de fertilizantes nas linhas de semeadura aumenta a variabilidade horizontal dos valores de teor de nutrientes em solos sob plantio direto, sobretudo no sentido perpendicular às linhas de semeadura. Isso é mais marcante para os nutrientes com baixa mobilidade no solo e maior efeito residual, como o P e o K (Salet et al., 1996; Kray et al., 1998), com grandes diferenças nos valores de teores desses nutrientes entre os locais adubados e os não-adubados, causando restrições à aleatorização das amostras simples.

A variabilidade dos índices de fertilidade do solo sob plantio direto (PD) geralmente é maior que sob cultivo convencional com revolvimento do solo mediante aração ou gradagem (PC), como conseqüência do não-revolvimento do solo e das aplicações localizadas de corretivos e fertilizantes. Quando no PD a adubação é feita a lanço, espera-se que a variabilidade horizontal seja semelhante à encontrada no PC. Contudo, se a adubação for feita em linha, a variabilidade deve ser maior no PD, principalmente na fase de implantação (até cinco anos), pois ocorre maior concentração de nutrientes nas linhas de adubação (Salet et al., 1996; Anghinoni \& Salet, 1998; Oliveira et al., 2002). Entretanto, Alvarez V. \& Guarçoni M. (2003) destacam o fato de que no $\mathrm{PC}$ a amostragem geralmente é feita depois da colheita e antes do revolvimento do solo subseqüente, fazendo com que no $\mathrm{PC}$ a variabilidade dos índices de fertilidade do solo seja semelhante àquela verificada no $\mathrm{PD}$.

A quantificação da variabilidade horizontal de alguns índices de fertilidade do solo sob PD, com diferentes modos de adubação e tempos de cultivo, foi realizada por Schlindwein \& Anghinoni (2000), em oito lavouras comerciais da região noroeste do Rio Grande do Sul. Foram coletadas 36 amostras simples, com pá de corte, na camada de $0-10 \mathrm{~cm}$, de forma diferenciada nas adubações a lanço (fatia com $5 \mathrm{~cm}$ de espessura por $10 \mathrm{~cm}$ de largura) e em linhas (5 cm de espessura da fatia pela largura das entrelinhas de semeadura da última cultura). Os teores de $\mathrm{P}$ e $\mathrm{K}^{+}$ apresentaram maior variabilidade; o de matéria orgânica (MO), variabilidade intermediária; e os valores de $\mathrm{pH}_{\mathrm{H}_{2} \mathrm{O}}$ e $\mathrm{pH}_{\mathrm{SMP}}$, menor variabilidade. A mesma ordem decrescente de variabilidade desses índices $\left(\mathrm{P}>\mathrm{K}^{+}>\mathrm{MO}>\mathrm{pH}_{\mathrm{H}_{2} \mathrm{O}}>\mathrm{pH}_{\mathrm{SMP}}\right)$ também foi verificada por Schlindwein \& Anghinoni (2002). A baixa variabilidade horizontal dos índices $\mathrm{MO}, \mathrm{pH}_{\mathrm{H}_{2} \mathrm{O}}$ e $\mathrm{pH}_{\text {SMP }}$ está relacionada com a distribuição uniforme da palhada e do calcário na superfície do solo. Por sua vez, a elevada variabilidade dos teores de $\mathrm{Pe} \mathrm{K}^{+}$é explicada pela aplicação localizada de fertilizantes predominantemente nas linhas de semeadura, que se mantêm pouco alteradas com o tempo de cultivo (Schlindwein \& Anghinoni, 2000).

A adequada representatividade da amostra composta está diretamente relacionada com a qualidade das amostras simples (Guarçoni M. et al., 2006). Entre outros requisitos, exige-se que as amostras simples sejam coletadas na mesma profundidade, possuam mesmo volume e reflitam as condições de fertilidade de seus respectivos sítios de coleta. Nesse sentido, em solos sob PD, onde a variabilidade horizontal (especialmente aquela perpendicular às linhas de adubação) dos índices de fertilidade do solo é elevada, o tipo de instrumento de coleta das amostras simples exercerá grande influência nas medidas da média e da variabilidade desses índices. Isso teria grande influência na determinação do número mínimo de amostras simples para formar uma amostra composta, na interpretação da análise de solo e nas recomendações de calagem e adubação.

Em área experimental há três anos manejada sob PD e numa área de lavoura há nove anos sob PD, ambas em Latossolo Vermelho distroférrico típico, Schlindwein \& Anghinoni (2002) avaliaram o efeito do tamanho da amostra simples (subamostra) de solo nas estimativas das variabilidades dos valores de teor de $\mathrm{P}$ e $\mathrm{K}^{+}$do solo, utilizando como instrumento de coleta a pá de corte. Os autores observaram que os coeficientes de variação de $\mathrm{P}$ e $\mathrm{K}^{+}$diminuíram, respectivamente, de acordo com o aumento do tamanho das amostras simples de $2,5 / 5$ para $5 / 10 \mathrm{~cm}$ na área experimental e de 2,2/2,5 para 5/10 na área de lavoura. Os autores também avaliaram a influência do instrumento de coleta (trado de rosca e pá de corte) da amostra de solo nas medidas da média e da variabilidade de características químicas de um Latossolo Vermelho muito argiloso. Para todas as características químicas analisadas $\left(\mathrm{pH}, \mathrm{pH}_{\mathrm{SMP}}, \mathrm{P}\right.$, $\mathrm{K}^{+}$e MO), independentemente da forma de adubação, a variabilidade foi maior quando se usou o trado de rosca do que quando se utilizou a pá de corte, principalmente para $P$.

A utilização do trado em substituição à pá de corte tem a vantagem da maior rapidez na coleta das amostras simples e no manuseio e transporte de um menor volume de solo no campo antes da homogeneização 
das amostras simples e retirada da amostra composta. Por outro lado, o menor volume de solo coletado com trado faz com que a variabilidade dos índices de fertilidade do solo aumente, tornando necessário coletar maior número de amostras simples para formar uma amostra composta representativa. Mesmo assim, a laboriosidade da amostragem de solo com a utilização do trado é menor do que quando se utiliza a pá de corte.

A princípio, o uso de instrumentos que coletam pequeno volume de solo, como o trado, não seria recomendável para o PD com adubação localizada na linha de plantio, preferindo-se o uso da pá de corte. Todavia, Alvarez V. \& Guarçoni M. (2003) afirmam que esse problema seria contornado se, durante a amostragem do solo sob PD ou sob PC depois da colheita e antes do subseqüente revolvimento do solo, $17 \%$ das amostras simples fossem coletadas no sulco de plantio, $33 \%$ a $10 \mathrm{~cm}$ do sulco e $50 \%$ no ponto médio entre sulcos, todas coletadas com trado de caneca.

Os objetivos deste trabalho foram avaliar os efeitos de instrumentos de coleta das amostras de solo (pá de corte e trado de caneca) e de tipos de preparo do solo (semeadura direta e preparo convencional do solo mediante seu revolvimento com arado e grade) nas medidas da média e da variabilidade dos principais índices de fertilidade do solo, bem como suas implicações na estimativa do número de amostras simples para formar uma amostra composta representativa; e demonstrar que a fertilidade média estimada a partir da média aritmética dos resultados das amostras simples é semelhante àquela estimada a partir da análise química da amostra composta, independentemente do tipo de preparo do solo e do instrumento de coleta das amostras.

\section{MATERIAL E MÉTODOS}

Para alcançar os objetivos propostos, foram coletadas, em agosto de 2004, amostras de solo em experimento de comparação de tipos de preparo do solo, que há sete anos vinha sendo realizado em um Luvissolo Crômico Pálico abrúptico (Embrapa, 2006) da estação experimental da Empresa Estadual de Pesquisa Agropecuária da Paraíba (EMEPA), localizada no município de Alagoinha, no Agreste do Estado da Paraíba.

Foram amostradas parcelas que receberam dois tipos de preparo do solo, cada uma medindo $81 \mathrm{~m}^{2}$. Antes da adoção dos dois tipos de preparo do solo foram realizadas uma aração (arado de discos) e duas gradagens (grade niveladora) em toda a área. Após a demarcação das parcelas, foram abertos sulcos com auxílio de enxada manual, para semeadura do milho no espaçamento de 1,0 x 0,20 m. A adubação consistiu da aplicação de $90 \mathrm{~kg} \mathrm{ha}^{-1}$ de N (sulfato de amônio), $80 \mathrm{~kg} \mathrm{ha}^{-1}$ de $\mathrm{P}_{2} \mathrm{O}_{5}$ (superfosfato simples) e $45 \mathrm{~kg} \mathrm{ha}^{-1}$ de $\mathrm{K}_{2} \mathrm{O}$ (cloreto de potássio). A dose de $\mathrm{P}$ e a de $\mathrm{Ke}$ um terço da dose de $\mathrm{N}$ foram aplicados em fundação, e o restante do N, 30 dias após a semeadura do milho. As adubações foram localizadas, colocando-se os adubos ao lado da linha de plantio, a aproximadamente $5 \mathrm{~cm}$ de profundidade.

A partir do segundo ano iniciou-se a adoção dos dois tipos de preparo do solo. O primeiro tipo consistia da semeadura direta do milho sem revolvimento do solo e com adubação localizada na linha de plantio (PD). No início do período chuvoso a vegetação espontânea da área era dessecada com herbicida (glyphosate); os restos culturais do milho e da vegetação espontânea eram deixados sobre a superfície do solo e, em seguida, abertos sulcos com enxada manual, para semeadura do milho. Durante o crescimento do milho, o controle das plantas daninhas foi feito com herbicida (nicosulfuron). Todas essas práticas de manejo foram adotadas nos anos subseqüentes. O período chuvoso da região começa em março e termina em agosto; as chuvas não são muito bem distribuídas durante esse período. Isso dificulta o cultivo de plantas de cobertura do solo antes ou após o cultivo do milho, razão pela qual tem sido difícil a manutenção de uma boa cobertura vegetal sobre a superfície do solo durante grande parte do ano. Assim, as parcelas eram ocupadas com monocultura de milho durante a estação chuvosa e com vegetação espontânea (pousio) + restos de cultura do milho durante a estação seca.

O segundo tipo de preparo do solo era feito de forma convencional (PC), em que, antes da semeadura do milho a cada ano, a vegetação espontânea era capinada com enxada manual e todos os restos culturais do milho e da vegetação espontânea eram queimados. Em seguida, o solo da camada superficial (0 a $15 \mathrm{~cm}$ ) de toda a área da parcela era revolvido com enxada manual antes da semeadura do milho. O espaçamento do milho e as práticas de adubação realizadas no PC foram os mesmos adotados no PD, exceto o controle de plantas daninhas, que no $\mathrm{PC}$ foi realizado por meio de capinas com enxadas manuais. No PC, as parcelas eram ocupadas com monocultura de milho durante a estação chuvosa e com vegetação espontânea (pousio) durante a estação seca.

Após a colheita do milho, foram coletadas amostras de solo em locais aleatoriamente distribuídos em toda a área de cada parcela, seguindo-se dois sistemas de amostragem. No primeiro, foi utilizada a pá de corte como instrumento de coleta, sendo retirada uma fatia de solo de $5 \mathrm{~cm}$ de espessura até a profundidade de $10 \mathrm{~cm}$, perpendicularmente aos sulcos e no espaço compreendido entre os pontos médios entre sulcos (100 cm, espaçamento utilizado no plantio de milho), de maneira que a linha de adubação e plantio ficasse centralizada na faixa de coleta (Schlindwein \& Anghinoni, 2002). O volume de cada amostra simples de solo coletada com pá de corte foi de $5 \mathrm{dm}^{3}$. Foram coletadas 24 amostras de solo com pá de corte para cada tipo de preparo do solo, no total de 48 amostras de solo coletadas com pá de corte. 
No outro sistema de amostragem, as amostras de solo foram coletadas com trado de caneca com $9,0 \mathrm{~cm}$ de diâmetro na camada de $0-10 \mathrm{~cm}$ de profundidade, próximas aos locais das amostras coletadas com pá de corte. O volume de cada amostra simples de solo coletada com trado foi de $0,64 \mathrm{dm}^{3}$. Também foram coletadas 24 amostras de solo para cada tipo de preparo do solo, no total de 48 amostras coletadas com trado de caneca. Quanto ao local de coleta das 24 amostras de solo coletadas com trado em cada tipo de preparo do solo, quatro delas foram retiradas do sulco de plantio, oito a $10 \mathrm{~cm}$ do sulco e doze no ponto médio entre os sulcos, conforme recomendação de Alvarez V. \& Guarçoni M. (2003).

Após serem coletadas no campo e devidamente identificadas, as 96 amostras de solo foram levadas para o Departamento de Solos e Engenharia Rural (DSER) do Centro de Ciências Agrárias (CCA) da Universidade Federal da Paraíba (UFPB), onde foram secas ao ar e depois passadas em peneira de $2 \mathrm{~mm}$ de malha.

Em cada tipo de preparo do solo, subamostras de cada amostra coletada com pá de corte e com trado de caneca foram utilizadas para simular a formação de cinco tipos de amostras compostas formadas por diferentes números de amostras simples, sendo: três compostas de 4 simples, três de 8 , três de 12 , três de 16 e três de 24. Foram preparadas 30 amostras compostas (dois tipos de preparo do solo $\mathrm{x}$ cinco tipos de amostra composta $\mathrm{x}$ três repetições) a partir de amostras simples coletadas com pá de corte e 30 amostras compostas a partir de amostras simples coletadas com trado de caneca, totalizando 60 amostras compostas.

Após preparação das amostras simples e compostas, elas foram analisadas quimicamente no Laboratório de Química e Fertilidade do Solo do DSER/CCA/ UFPB, sendo determinados o $\mathrm{pH}_{\mathrm{H}_{2} \mathrm{O}}$ e os teores de $\mathrm{P}$, $\mathrm{K}^{+}, \mathrm{Ca}^{2+}, \mathrm{Mg}^{2+}$ e matéria orgânica, conforme Embrapa (1997). Após obtenção e tabulação dos dados, estes foram submetidos à análise estatística.

Foram determinados a média e o coeficiente de variação para cada um dos quatro grupos de amostras simples. Em seguida, foi determinado o número mínimo de amostras simples que teoricamente deveria ser utilizado para formação de uma amostra composta representativa da parcela, para os quatro grupos de 24 amostras simples e para as características químicas que apresentaram maior variabilidade, conforme procedimento estatístico adotado por Barreto et al. (1974):

$$
\mathrm{n}=\left[\left(\mathrm{t}_{\alpha / 2} \cdot \mathrm{CV}\right) / \mathrm{f}\right]^{2}
$$

em que $\mathrm{n}=$ número de amostras simples para formar uma composta representativa; $\mathrm{t}_{\alpha / 2}=$ valor tabelado da distribuição t de Student, o qual depende do nível $\alpha / 2$ de probabilidade (bilateral) e do número de graus de liberdade (n-1); CV = coeficiente de variação da característica do solo a ser avaliada; e f = erro admitido em torno da média (\%).
Por meio do teste t de Student, para cada tipo de preparo do solo, foi testada a hipótese de que a fertilidade média do solo avaliada com trado de caneca é semelhante àquela avaliada com pá de corte, desde que $17 \%$ das amostras simples sejam coletadas no sulco de plantio, $33 \%$ a $10 \mathrm{~cm}$ do sulco e $50 \%$ no ponto médio entre sulcos. As variâncias foram comparadas utilizando-se o teste $\mathrm{F}$.

Foram feitas análises de variância e de regressão no delineamento inteiramente casualizado com três repetições e 20 tratamentos, resultantes da combinação fatorial entre dois métodos de avaliação da fertilidade média do solo (média aritmética de amostras simples e análise química da amostra composta), dois tipos de preparo do solo (PD e PC) e cinco diferentes números de amostras simples (4, 8, 12, 16 e 24 amostras simples), para formar uma amostra composta, a fim de testar os efeitos de tipos de preparo do solo e do tamanho da amostra composta nas estimativas das médias dos índices de fertilidade do solo. Todas as análises estatísticas foram realizadas usando-se os softwares SAEG (Ribeiro Júnior, 2001) e Microsoft Excel.

\section{RESULTADOS E DISCUSSÃO}

O teor de MO avaliado em amostras de solo sob $\mathrm{PD}$ e coletadas com trado foi superior àquele obtido em amostras de solo coletadas com pá de corte; no $\mathrm{PC}$, o teor de $\mathrm{Mg}^{2+}$ avaliado em amostras de solo coletadas com trado foi superior ao avaliado em amostras de solo coletadas com pá de corte (Quadro 1). Para $\mathrm{P}, \mathrm{K}^{+}, \mathrm{Ca}^{2+}$ e $\mathrm{pH}$, nos dois tipos de preparo do solo, e para $\mathrm{Mg}^{2+}$ no $\mathrm{PD}$ e $\mathrm{MO}$ no $\mathrm{PC}$, não houve diferenças nos valores obtidos de ambos os instrumentos de coleta (Quadro 1). Portanto, em quase todas as comparações os valores dos índices de fertilidade do solo foram semelhantes, com exceção do teor de $\mathrm{MO}$ no PD e do teor de $\mathrm{Mg}^{2+}$ no $\mathrm{PC}$, onde a coleta de solo com trado superestimou os valores dos índices de fertilidade, quando comparado com a pá de corte (Quadro 1). Assim, este trabalho confirma a recomendação de Alvarez V. \& Guarçoni M. (2003), de que a fertilidade média de uma gleba de solo sob PD ou sob PC, após a colheita e antes do novo preparo do solo, pode ser avaliada com o trado de caneca, em substituição à pá de corte, desde que na preparação da amostra composta de solo $17 \%$ das amostras simples sejam coletadas no sulco de plantio, $33 \%$ a $10 \mathrm{~cm}$ do sulco e $50 \%$ no ponto médio entre os sulcos. Mesmo com resultados diferentes para MO no PD, essa recomendação é válida na prática, já que a magnitude das diferenças observadas entre os instrumentos (Quadro 1) é pequena e insuficiente para influenciar a interpretação da análise de solo e a recomendação de adubação das culturas, conforme Ribeiro et al. (1999). 
Para $\mathrm{Mg}^{2+}$ no $\mathrm{PC}$, a magnitude da diferença observada entre os instrumentos é grande, o que poderia influenciar a interpretação da análise de solo para esse nutriente e, conseqüentemente, a recomendação da necessidade de calagem para esse solo no PC. Essa diferença entre os instrumentos de coleta para $\mathrm{Mg}^{2+}$ no $\mathrm{PC}$ foi uma exceção à regra e não invalida a proposição de Alvarez V. \& Guarçoni M. (2003).

$\mathrm{O}$ teor de $\mathrm{Mg}^{2+}$ elevado no solo sob PC, nas amostras coletadas com trado, pode ser resultado de possíveis variações intensas e a curtas distâncias dos valores do teor de $\mathrm{Mg}^{2+}$ no solo. Por coletar solo em menor área superficial do solo e, conseqüentemente, menor volume de solo $\left(0,64 \mathrm{dm}^{3}\right)$ em comparação com a pá de corte $\left(5 \mathrm{dm}^{3}\right)$, o trado possivelmente não detectou essas variações nos valores de teor de $\mathrm{Mg}^{2+}$ a curtas distâncias. Essa hipótese pode ser comprovada pelo fato de o valor desta característica nas amostras coletadas com pá de corte no PC ter se aproximado do valor das amostras coletadas com ambos os instrumentos no PD, mostrando a tendência do real valor desse elemento no solo.

A variabilidade dos índices de fertilidade do solo foi diferente entre os instrumentos de coleta, sendo observados maiores valores para o trado de caneca do que para a pá de corte, independentemente do tipo de preparo do solo, com exceção dos teores de $\mathrm{K}^{+} \mathrm{e} \mathrm{Ca}^{2+}$ no PC, que foram iguais (Quadro 1). Independentemente do instrumento de coleta das amostras, o P apresentou maior variabilidade e o $\mathrm{pH}$ menor, de acordo com a seguinte ordem decrescente: $\mathrm{P}>\mathrm{Mg}^{2+}>\mathrm{K}^{+}>$ $\mathrm{Ca}^{2+}>\mathrm{MO}>\mathrm{pH}$ (Quadro 1). Essa mesma ordem de variabilidade foi verificada por Alvarez V. \& Guarçoni M. (2003), tanto para a pá de corte como para o trado. Schlindwein \& Anghinoni (2002) encontraram valores semelhantes de coeficientes de variação para $\mathrm{K}^{+}$,
pH e $\mathrm{MO}$ em um solo sob PD e menores para $\mathrm{P}$ em amostras coletadas com trado.

Para os três índices de fertilidade do solo que apresentaram maior variabilidade, foi calculado o número de amostras simples que seria necessário para formar uma amostra composta representativa (Quadro 2). Com exceção de $\mathrm{Mg}^{2+}$ no PD e P nos dois tipos de preparo do solo, ambos os nutrientes avaliados em amostras coletadas com trado, a coleta de 10 a 20 amostras simples para formar uma amostra composta seria suficiente para avaliar a fertilidade média de uma gleba de solo sob PD ou PC, independentemente do instrumento de coleta das amostras, admitindo-se um erro de $20 \%$ em torno da média.

Resultados semelhantes a estes (10 a 20 amostras simples para formar uma composta) foram encontrados por Salet et al. (1996) em diferentes lavouras sob PC e PD, considerando $\alpha=5 \%$ e f $=20 \%$. Os autores encontraram ainda elevado número de amostras simples para avaliações de $\mathrm{Pe} \mathrm{K}^{+}$considerando erro de $10 \%$. Contudo, Schlindwein \& Anghinoni (2000) afirmam que adotar erro de $10 \%$ em condições de lavoura seria excesso de rigor para a exatidão da amostragem, visto que podem ocorrer ainda erros laboratoriais, que influenciam a recomendação de calagem e adubação. Alvarez V. \& Guarçoni M. (2003) encontraram valores inferiores a esses, admitindo-se o mesmo erro em torno da média, tanto para a pá de corte como para o trado, em um solo há 15 anos sob PD. Schlindwein \& Anghinoni (2002), estudando solos sob PD com adubação em linha e a lanço, também encontraram esse número de amostras simples para formar uma composta como o ideal para representar a fertilidade média das áreas estudadas, admitindose esse erro em torno da média. Entretanto, os autores observaram que o número de amostras simples coletadas com trado para formar uma composta seria

Quadro 1. Médias ${ }^{(1)}$ e coeficientes de variação ${ }^{(2)}$ para os teores de fósforo, potássio, cálcio, magnésio e matéria orgânica (MO) e para o pH em amostras de solo coletadas com pá de corte e com trado de caneca, em parcelas sob plantio direto e preparo convencional do solo
Instrumento de coleta
$\mathbf{P}$
$\mathbf{K}^{+}$
$\mathrm{Ca}^{2+} \quad \mathbf{M g}^{2+}$
MO
pH

\begin{tabular}{|c|c|c|c|c|c|c|}
\hline \multirow[b]{3}{*}{ Pá de corte } & \multirow[t]{2}{*}{$\mathrm{mg} \mathrm{dm} \mathrm{m}^{-3}$} & \multicolumn{3}{|c|}{$\mathrm{cmol}_{\mathrm{c}} \mathrm{dm}^{-3}$} & \multirow[t]{2}{*}{$\mathrm{g} \mathrm{kg}^{-1}$} & \multirow[b]{3}{*}{$5,4 \mathrm{a}(3 \mathrm{~b})$} \\
\hline & & \multicolumn{3}{|c|}{ Plantio direto } & & \\
\hline & $14,3 \mathrm{a} \quad(33 \mathrm{~b})$ & $0,20 \mathrm{a}(16 \mathrm{~b})$ & $2,04 \mathrm{a}(12 \mathrm{~b})$ & $0,85 a(21 b)$ & $11,7 b(11 b)$ & \\
\hline \multirow[t]{2}{*}{ Trado } & $24,1 \mathrm{a}(125 \mathrm{a})$ & $0,18 \mathrm{a}(36 \mathrm{a})$ & $2,17 \mathrm{a}(22 \mathrm{a})$ & $0,77 \mathrm{a}(47 \mathrm{a})$ & $12,9 a(18 a)$ & $5,5 \mathrm{a}(7 \mathrm{a})$ \\
\hline & \multicolumn{6}{|c|}{ Preparo convencional do solo } \\
\hline Pá de corte & $14,6 \mathrm{a} \quad(31 \mathrm{~b})$ & $0,24 a(21 a)$ & $2,33 \mathrm{a}(14 \mathrm{a})$ & $0,79 b(21 b)$ & $12,7 \mathrm{a} \quad(9 \mathrm{~b})$ & $5,7 \mathrm{a}(3 \mathrm{~b})$ \\
\hline Trado & $20,3 a(108 a)$ & $0,21 \mathrm{a}(26 \mathrm{a})$ & $2,25 a(19 a)$ & $1,34 \mathrm{a}(38 \mathrm{a})$ & $13,3 \mathrm{a}(17 \mathrm{a})$ & $5,8 \mathrm{a}(6 \mathrm{a})$ \\
\hline
\end{tabular}

${ }^{(1)}$ Médias seguidas de mesma letra, na coluna e dentro de cada tipo de preparo do solo, não diferem significativamente pelo teste t de Student a $5 \% . \mathrm{n}=24 .{ }^{(2)}$ Valores entre parênteses, dados em percentagem. Aplicou-se o teste F para comparar as variâncias. Portanto, coeficientes de variação seguidos da mesma letra, na coluna e dentro de cada tipo de preparo do solo, significa que as variâncias são iguais pelo teste $\mathrm{F}$ a $5 \%$. 
maior que 20 para avaliação do teor de $\mathrm{P}$ no solo, semelhante ao encontrado neste trabalho.

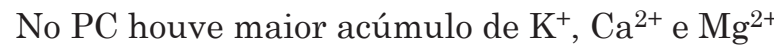
no solo e maior valor de $\mathrm{pH}$, quando comparado ao $\mathrm{PD}$ (Quadro 3); para P e MO, não houve diferença entre os tipos de preparo do solo. De modo geral, verifica-se que o não-revolvimento do solo e a não-incorporação dos resíduos vegetais de milho e de vegetação espontânea ao solo sob PD não aumentaram os teores de nutrientes e de matéria orgânica na camada de solo até $10 \mathrm{~cm}$ de profundidade. Isso provavelmente se deveu à ausência do plantio de plantas de cobertura do solo antes ou após o cultivo do milho e à pequena quantidade de matéria seca produzida pela vegetação espontânea. Por sua vez, essas práticas adotadas no PD contribuíram para aumentar a acidez do solo na camada de $0-10 \mathrm{~cm}$ e, talvez, tenham contribuído para

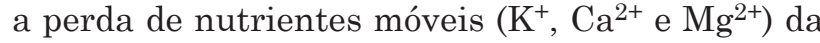
camada mais superficial do solo (Quadro 3), possivelmente por lixiviação. Vários trabalhos têm mostrado que no PD a infiltração da água no solo é maior que no PC (Centurion \& Demattê, 1985; Barcelos et al., 1999; Cruz et al., 2003; Reichert et al., 2005).

Quanto à variabilidade dos índices de fertilidade do solo, ela foi igual entre os preparos PD e PC (Quadro 3) na maioria dos casos. Isso é a comprovação da hipótese levantada por Alvarez V. \& Guarçoni M. (2003), de que a variabilidade dos índices de fertilidade do solo sob $\mathrm{PD}$ é semelhante àquela avaliada no $\mathrm{PC}$ depois da colheita e antes do preparo do solo subseqüente.

De modo geral, os teores médios de $\mathrm{P}, \mathrm{K}^{+}, \mathrm{Ca}^{2+}, \mathrm{Mg}^{2+}$ e $\mathrm{MO}$ e o valor de $\mathrm{pH}$ do solo podem ser avaliados tanto pela média aritmética dos valores encontrados nas amostras simples como pela análise química da amostra composta, seja no PD ou no PC (Quadros 4 e 5). Foge dessa regra o $\mathrm{pH}$ nos dois tipos de preparo do solo, onde a análise química da amostra composta

Quadro 2. Número de amostras simples calculado para formar uma amostra composta ${ }^{(1)}$ para avaliar os teores de fósforo, potássio e magnésio, considerando o instrumento de coleta da amostra de solo, os tipos de preparo do solo e o erro admitido em torno da média verdadeira

\begin{tabular}{|c|c|c|c|c|c|c|}
\hline \multirow{2}{*}{ Erro em relação à média } & \multicolumn{2}{|c|}{$\mathbf{P}$} & \multicolumn{2}{|c|}{$\mathbf{K}^{+}$} & \multicolumn{2}{|c|}{$\mathrm{Mg}^{2+}$} \\
\hline & Pá & Trado & Pá & Trado & Pá & Trado \\
\hline$\%$ & \multicolumn{6}{|c|}{ Plantio direto } \\
\hline 20 & 12 & 168 & 3 & 14 & 5 & 24 \\
\hline 15 & 21 & 298 & 5 & 25 & 8 & 42 \\
\hline \multirow[t]{2}{*}{10} & 48 & 671 & 10 & 55 & 18 & 95 \\
\hline & \multicolumn{6}{|c|}{ Preparo convencional do solo } \\
\hline 20 & 11 & 125 & 5 & 7 & 5 & 15 \\
\hline 15 & 19 & 222 & 9 & 12 & 8 & 28 \\
\hline 10 & 42 & 500 & 20 & 28 & 18 & 62 \\
\hline
\end{tabular}

(1) $\mathrm{n}=\left[\left(\mathrm{t}_{\alpha / 2} \cdot \mathrm{CV}\right) / \mathrm{f}\right]^{2}$ conforme Barreto et al. (1974).

Quadro 3. Médias ${ }^{(1)}$ e coeficientes de variação ${ }^{(2)}$ para os teores de fósforo, potássio, cálcio, magnésio, matéria orgânica (MO) e para o pH, de acordo com o tipo de preparo do solo, independentemente do instrumento de coleta da amostra de solo

\begin{tabular}{|c|c|c|c|c|c|c|}
\hline Tipo de preparo do solo & $\mathbf{P}$ & $\mathbf{K}^{+}$ & $\mathrm{Ca}^{2+}$ & $\mathrm{Mg}^{2+}$ & MO & pH \\
\hline & $\mathrm{mg} \mathrm{dm} \mathrm{m}^{-3}$ & - & $\mathrm{cmol}_{\mathrm{c}} \mathrm{dm}^{-3}$ & - & $\mathrm{g} \mathrm{kg}^{-1}$ & \\
\hline $\mathrm{PD}$ & $19,21 \mathrm{a}(114 \mathrm{a})$ & $0,19 b(27 a)$ & $2,10 \mathrm{~b}(18 \mathrm{a})$ & $0,81 b(35 b)$ & $12,31 \mathrm{a}(16 \mathrm{a})$ & $5,5 \mathrm{~b}(5 \mathrm{a})$ \\
\hline $\mathrm{PC}$ & $17,42 \mathrm{a} \quad(91 \mathrm{~b})$ & $0,23 a(24 a)$ & $2,29 a(16 a)$ & $1,06 a(44 a)$ & $12,96 a(14 a)$ & $5,7 a(5 a)$ \\
\hline
\end{tabular}

\footnotetext{
${ }^{(1)}$ Médias seguidas de mesma letra, na coluna, não diferem significativamente pelo teste t de Student a $5 \%$. $\mathrm{n}=48$. ${ }^{(2)}$ Valores entre parênteses, dados em percentagem. Aplicou-se o teste $\mathrm{F}$ para comparar as variâncias. $\mathrm{n}=48$. Portanto, coeficientes de variação seguidos da mesma letra, na coluna, significam que as variâncias são iguais pelo teste $\mathrm{F}$ a 5 \%
} 
Quadro 4. Médias ${ }^{(1)}$ e coeficientes de variação ${ }^{(2)}$ para os teores de fósforo, potássio e magnésio no solo, avaliados pela média aritmética de resultados de análises químicas de amostras simples e pela análise química da amostra composta, considerando o número de amostras simples para formar uma amostra composta, no plantio direto e no preparo convencional do solo

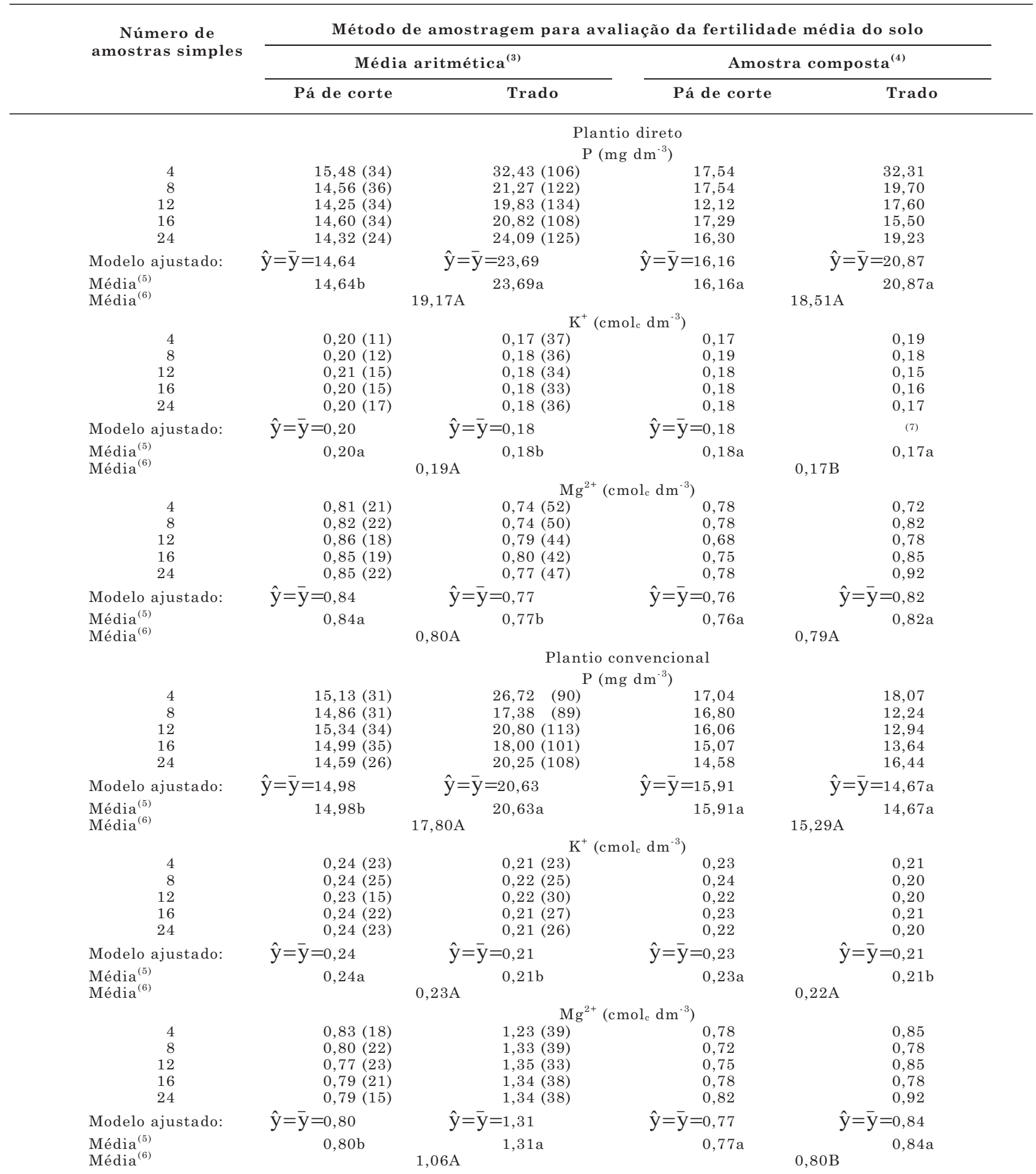

${ }^{(1)}$ Os resultados apresentados são médias de três repetições. ${ }^{(2)}$ Valores entre parênteses, dados em percentagem, são médias de três repetições. ${ }^{(3)}$ Analisou-se quimicamente cada amostra simples separadamente e calculou-se a média aritmética dos resultados. ${ }^{(4)}$ Analisou-se quimicamente apenas uma amostra composta. ${ }^{(5)}$ Médias seguidas de mesma letra minúscula, na linha, dentro de cada método de amostragem para avaliação da fertilidade média do solo, não diferem entre si pelo teste $\mathrm{F}$ a $5 \%$. ${ }^{(6)}$ Médias seguidas de uma mesma letra maiúscula, na linha, não diferem entre si pelo teste $\mathrm{F}$ a $5 \%$. ${ }^{(7)}$ Modelo ajustado: $\hat{\mathrm{y}}=87,98$ $3,5347 * * \mathrm{NAS}+0,1122 * * \mathrm{NAS}^{2}$, com $\mathrm{R}^{2}=0,91$. 
Quadro 5. Médias ${ }^{(1)}$ e coeficientes de variação ${ }^{(2)}$ para pH e teores de cálcio e matéria orgânica (MO) do solo, avaliados pela média aritmética de resultados de análises químicas de amostras simples e pela análise química da amostra composta, considerando o número de amostras simples para formar uma amostra composta, no plantio direto e no preparo convencional do solo

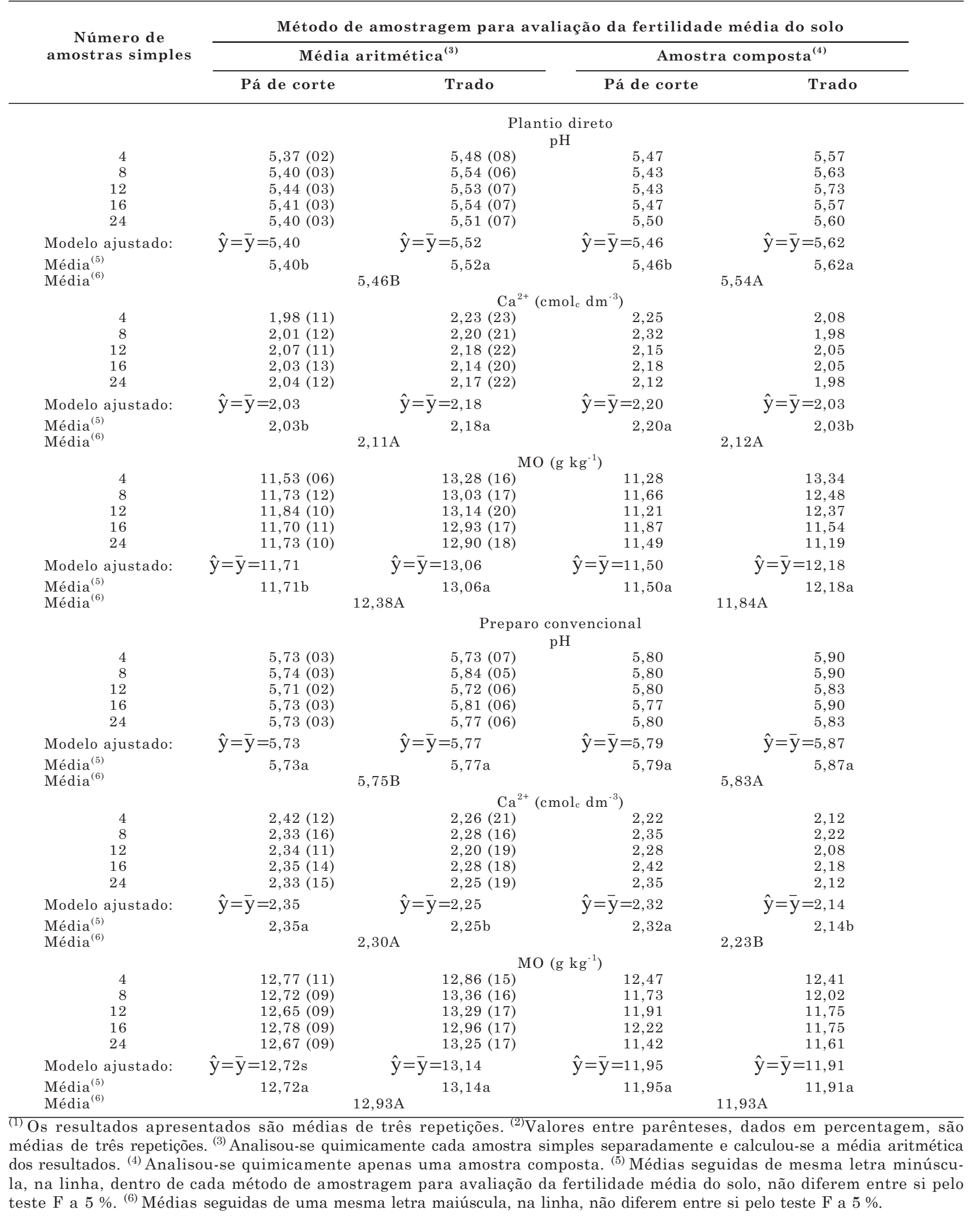


superestimou o resultado deste índice de fertilidade,

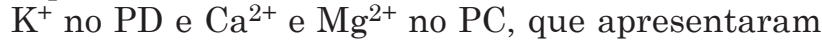
comportamento contrário, com maiores valores obtidos pela média aritmética das amostras simples. A semelhança entre os métodos de amostragem (média aritmética e amostra composta) também pode ser observada dentro de cada instrumento de coleta (Quadros 4 e 5).

Quanto ao efeito do instrumento de coleta das amostras de solo, verificaram-se diferenças entre a pá de corte e o trado de caneca na avaliação dos valores dos teores médios de todos os índices de fertilidade do solo quando a fertilidade média foi avaliada pela média aritmética das amostras simples, tanto no PD como no PC (Quadros 4 e 5), menos para pH e $\mathrm{MO}$ no PC. Quando os teores médios desses nutrientes no solo foram avaliados a partir da análise química da amostra composta, que é o que se faz na prática, a pá de corte e o trado de caneca não apresentaram diferenças na maioria dos casos, existindo diferenças apenas para $\mathrm{Ca}^{2+}$ em ambos os sistemas de cultivo, pH no PD e K ${ }^{+}$no PC. Isso confirma a proposição de Alvarez V. \& Guarçoni M. (2003), citada anteriormente, de que uma amostragem obtida com trado de caneca pode substituir a amostragem feita com pá de corte nos preparos PD e PC depois da colheita e antes do preparo do solo subseqüente, quando se pretende avaliar a fertilidade média de uma gleba de terra.

Independentemente do método de amostragem para avaliação da fertilidade média do solo (média aritmética de amostras simples ou análise química da amostra composta) e do instrumento de coleta das amostras (pá de corte ou trado de caneca), o número de amostras simples para formar uma amostra composta não teve influência na estimativa dos teores médios de todas as características avaliadas, tanto para o PD como para o PC. Os dados de coeficientes de variação de todas as características avaliadas, independentemente do método de amostragem para avaliação da fertilidade média do solo e do instrumento de coleta das amostras, também não apresentaram nenhuma tendência de variação com o aumento do número de amostras simples para formar uma amostra composta, tanto no PD quanto no PC (Quadros 4 e 5).

De acordo com a fórmula estatística que determina o número de amostras simples para formar uma composta representativa (Barreto et al., 1974), a coleta de maior número de amostras simples (maior valor de $n$ ) não tem influência no valor médio da característica química do solo avaliada, mas aumenta a confiabilidade ou exatidão dessa média obtida, pela diminuição do valor de "f". Quanto à variabilidade dessa média (CV), esta tende a não mudar quando se aumenta o valor de "n", porque, ao mesmo tempo em que o valor de "n" aumenta, o de "f" diminui.

\section{CONCLUSÃO}

1. De modo geral, a variabilidade dos índices de fertilidade do solo foi maior para o trado de caneca do que para a pá de corte, independentemente do tipo de preparo do solo. Para os dois instrumentos de coleta das amostras, o $\mathrm{P}$ apresentou a maior variabilidade $\mathrm{e}$ o $\mathrm{pH}$ a menor, de acordo com a seguinte ordem decrescente: $\mathrm{P}>\mathrm{Mg}^{2+}>\mathrm{K}^{+}>\mathrm{Ca}^{2+}>\mathrm{MO}>\mathrm{pH}$. Observou-se maior variabilidade para $\mathrm{P}$ e menor para $\mathrm{Mg}^{2+}$ no plantio direto (PD), quando comparado com o preparo convencional (PC), porém os dois tipos de preparo do solo foram semelhantes quanto à variabilidade de $\mathrm{K}^{+}, \mathrm{Ca}^{2+}$, $\mathrm{MO}$ e $\mathrm{pH}$.

2. A fertilidade média de uma gleba de solo sob PD ou sob PC após a colheita e antes do preparo do solo subseqüente pode ser avaliada com o trado de caneca, em substituição à pá de corte, desde que na preparação da amostra composta de solo $17 \%$ das amostras simples sejam coletadas no sulco de plantio, $33 \%$ a $10 \mathrm{~cm}$ do sulco e $50 \%$ no ponto médio entre os sulcos. Foram observados menores teores de $\mathrm{K}^{+}, \mathrm{Ca}^{2+} \mathrm{e} \mathrm{Mg}^{2+}$ e menor pH no solo sob PD do que no solo sob PC. Para $\mathrm{P}$ e MO, não houve diferenças entre os sistemas $\mathrm{PD}$ e $\mathrm{PC}$.

3. A fertilidade média do solo de uma unidade de amostragem sob PD ou sob PC depois da colheita e antes do preparo do solo subseqüente, avaliada pela análise química da amostra composta, é semelhante àquela avaliada pela média aritmética das análises químicas das amostras simples coletadas com pá de corte ou com trado de caneca de forma dirigida, conforme utilizado neste trabalho.

4. Em geral, a coleta de pelo menos oito amostras simples de solo realizada com pá de corte ou trado de caneca de forma dirigida, como utilizado neste trabalho, seria suficiente para formar uma amostra composta representativa para avaliação da fertilidade média do solo de uma unidade de amostragem aparentemente homogênea. Contudo, quanto maior o número de amostras simples coletadas, maior será a confiabilidade ou exatidão da estimativa dessa fertilidade média.

\section{LITERATURA CITADA}

ALVAREZ V., V.H. \& GUARÇONI M., A. Variabilidade horizontal da fertilidade do solo de uma unidade de amostragem em sistema plantio direto. R. Bras. Ci. Solo, 27:297-310, 2003.

ANGHINONI, I. \& SALET, R.L. Amostragem do solo e as recomendações de adubação e calagem no sistema plantio direto. In: NUERNBERG, N.J., ed. Conceitos e fundamentos do sistema plantio direto. Lages, Sociedade Brasileira de Ciência do Solo, 1998. p.27-52. 
BARCELOS, A.A.; CASSOL, E.A. \& DENARDIN, J.E. Infiltração de água em um Latossolo Vermelho-Escuro sob condições de chuva intensa em diferentes sistemas de manejo. R. Bras. Ci. Solo, 23:35-43, 1999.

BARRETO, A.C.; NOVAIS, R.F. \& BRAGA, J.M. Determinação estatística do número de amostras simples de solo por área para avaliação de sua fertilidade. R. Ceres, 21:142147, 1974.

CENTURION, J.F. \& DEMATTÊ, J.L.I. Efeitos de sistemas de preparo nas propriedades físicas de um solo sob cerrado cultivado com soja. R. Bras. Ci. Solo, 9:263-266, 1985.

CRUZ, A.C.R.; PAULETTO, E.A.; FLORES C.A. \& SILVA J.B. Atributos físicos e carbono orgânico de um Argissolo Vermelho sob sistemas de manejo. R. Bras. Ci. Solo, 27:1105-1112, 2003

EMPRESA BRASILEIRA DE PESQUISA AGROPECUÁRIA EMBRAPA. Centro Nacional de Pesquisa de Solos. Sistema Brasileiro de Classificação de Solos. Rio de Janeiro, Embrapa Solos, 2006. 306p.

EMPRESA BRASILEIRA DE PESQUISA AGROPECUÁRIA EMBRAPA. Manual de métodos de análise de solo. Rio de Janeiro, 1997. 212p.

GUARCONI M., A.; ALVAREZ V., V.H.; NOVAIS, R.F.; CANTARUTTI, R.B.; LEITE, H.G. \& FREIRE, F.M. Definição da dimensão do indivíduo solo e determinação do número de amostras simples necessário à sua representação. R. Bras. Ci. Solo, 30:943-954, 2006.

JAMES, D.W. \& WELLS, K.L. Soil sample collection and handling: Technique based on source and degree of field variability. In: WESTERMAN, R.L., ed. Soil testing and plant analysis. Madison, Soil Science Society of America, 1990. p.25-44. (SSSA Book Series, 3)

KRAY, C.H.; SALET, R.L. \& ANGHINONI, I. Variabilidade horizontal e amostragem do solo dirigida no sistema plantio direto. Porto Alegre, Universidade Federal do Rio Grande do Sul, 1998. 6p. (Relatório de pesquisa)

MAUSBACH, M.J. \& WILDING, L.P. Spatial variabilities of soils and landforms. Madison, Soil Science Society of America, 1991. 270p. (SSSA Special Publication, 28)
OLIVEIRA, F.H.T.; NOVAIS, R.F.; ALVAREZ V., V.H.; CANTARUTTI, R.B. \& BARROS, N.F. Fertilidade do solo no sistema plantio direto. In: ALVAREZ V., V.H.; SCHAEFER, C.E.G.R; BARROS, N.F.; MELLO, J.W.V. \& COSTA, L.M., eds. Tópicos em ciência do solo. Viçosa, MG, Sociedade Brasileira de Ciência do Solo, 2002. p.393486.

REICHERT, J.M.; REINERT, D.J.; CASSOL, E.A. \& SILVA, V.R. A infiltração da água no solo sob sistema conservacionista. In: CONGRESSO BRASILEIRO DE CIÊNCIA DO SOLO, 30., Recife, 2005. Anais. Recife, Sociedade Brasileira de Ciência do Solo/Universidade Federal Rural de Pernambuco, 2005. 12p. CD ROM

RIBEIRO JÚNIOR, J.I. Análises estatísticas no SAEG. Viçosa, MG, Universidade Federal de Viçosa, 2001. 301p.

RIBEIRO, A.C.; GUIMARÃES, P.T.G. \& ALVAREZ V., V.H., eds. Recomendações para o uso de corretivos e fertilizantes em Minas Gerais: $5^{a}$ aproximação. Viçosa, CFSEMG, 1999. 359p.

SALET, R.L.; KRAY, C.H.; FORNARI, T.G.; CONTE, E.; KOCHHANN, R.A. \& ANGHINONI, I. Variabilidade horizontal e amostragem de solo no sistema plantio direto. In: REUNIÃO SUL-BRASILEIRA DE CIÊNCIA DO SOLO, 1., Lages, 1996. Resumos Expandidos. Lages, Sociedade Brasileira de Ciência do Solo, 1996. p.74-76.

SANTOS, H.L. \& VASCONCELOS, C.A. Determinação do número de amostras de solo para análise química em diferentes condições de manejo. R. Bras. Ci. Solo, 11:97100, 1987.

SCHLINDWEIN, J.A. \& ANGHINONI, I. Tamanho da subamostra e representatividade da fertilidade do solo no sistema plantio direto. Ci. Rural, 32:963-968, 2002.

SCHLINDWEIN, J.A. \& ANGHINONI, I. Variabilidade horizontal de atributos de fertilidade e amostragem do solo no sistema plantio direto. R. Bras. Ci. Solo, 24:85-91, 2000.

VASCONCELOS, C.A.; SANTOS, H.L.; BAHIA FILHO, A.F.C.; OLIVEIRA, A.C. \& PACHECO, E.B. Amostragem de solo em área com adubação fosfatada aplicada a lanço e no sulco de plantio. R. Bras. Ci. Solo, 6:221-225, 1982. 